DOI 10. 18307/2021. 0613

(C) 2021 by Journal of Lake Sciences

\title{
土地利用与覆被变化对巢湖湖滨带土壤有机碳组分及酶活性的 影响”
}

杨长明**, 陈霞智, 张一酸, 范博博

(同济大学长江水环境教育部重点实验室,上海 200092)

摘 要: 为了揭示湖滨带土地利用与覆被改变对土壤有机碳库及生态功能的影响, 本文选取了巢湖湖滨带 (北岸) 9 个典 型样方, 分析和比较了表层 $(0 \sim 30 \mathrm{~cm})$ 土壤有机碳组分特征以及相关酶的活性. 结果表明, 巢湖湖滨带不同采样点土壤总 有机碳 (TOC) 含量变化范围为 $2.88 \sim 11.2 \mathrm{~g} / \mathrm{kg}$, 平均含量为 $9.12 \mathrm{~g} / \mathrm{kg}$, 其中原生芦苇 (Phragmites australis) 湿地土壤 TOC 含量最高 $(11.2 \mathrm{~g} / \mathrm{kg})$, 而芦苇群落消失后形成的荒滩土壤 TOC 含量最低, 仅为 $2.88 \mathrm{~g} / \mathrm{kg}$. 表征湖滨带湿地缓冲性能的土 壤阳离子交换量 (CEC) 也以原生芦苇湿地土壤为最高, 并与 TOC 含量呈现明显正相关. 湖滨带表层土壤溶解性有机碳 (DOC) 和易氧化有机碳 (EOC) 含量变化范围分别为 $150 \sim 370 \mathrm{mg} / \mathrm{kg}$ 和 $1.7 \sim 5.2 \mathrm{~g} / \mathrm{kg}$, 其变化幅度明显高于 TOC, 其中 DOC 含量各采样点差异最为显著. 除多酚氧化酶外, 次生水柳林 (Homonoia riparia Lour.) 表层土壤几种酶的活性较原生 芦苇湿地土壤皆有所上升, 特别是蔗糖酶活性增加幅度最为明显. 受人类活动干扰较大的湖滨绿地公园和人工草滩土壤 过氧化氢酶、䐂酶和蔗糖酶酶活性普遍显著低于原生芦苇湿地. 除多酚氧化酶外, 土壤中几种酶活性与土壤有机碳组分 EOC 和 DOC 含量均呈现显著的正相关, 其中蔗糖酶活性与 DOC 含量之间相关系数最高 $(r=0.907)$, 其相关性均达到极显 著水平. 土壤溶解性有机碳和蔗糖酶可以作为表征因土地利用与覆被变化导致湖滨带湿地退化以及生态恢复效果的敏 感性指标.

关键词 : 巢湖; 湖滨带湿地;土地利用与覆盖变化;溶解性有机碳; 蔗糖酶活性

\section{Effect of land use and cover change on soil organic carbon fractions and enzymatic activi- ties in lakeshore wetland of north shore of Lake Chaohu*}

Yang Changming ${ }^{* *}$, Chen Xiazhi, Zhang Yixian \& Fan Bobo

( Key Laboratory of Yangtze River Water Environment of the Ministry of Education, Tongji University, Shanghai 200092, P.R. China)

Abstract: In order to explore the effect of land use and cover change on lakeshore soil organic carbon sequestration and it ecological function, nine typical sample plots with different plantations along the north shore of Lake Chaohu were investigated, and the surface soils $(0-30 \mathrm{~cm})$ organic carbon fractions and the enzymes activities were analyzed and compared. The results showed that soil total organic carbon ( TOC) was $2.88-11.2 \mathrm{~g} / \mathrm{kg}$, with an average of $9.12 \mathrm{~g} / \mathrm{kg}$. The soil under native Phragmites australis reed wetland showed the highest TOC content, and the TOC content in the wasteland formed after the disappearance of $P$. australis reed community was the lowest with the value of only $2.88 \mathrm{~g} / \mathrm{kg}$. The cation exchange capacity ( CEC), which can be used to characterize the buffer performance of lakeside zone, was highest in the native P.australis reed wetland soil and positively correlated with TOC. Soil labile organic carbon fractions content, including dissolved organic carbon (DOC) and easily oxidized organic carbon (EOC) from the lakeshore wetland, ranged from 150 to $370 \mathrm{mg} / \mathrm{kg}$ and from 1.7 to $5.2 \mathrm{~g} / \mathrm{kg}$, respectively. The range of change in soil DOC and EOC between different sampling sites was larger than that in TOC. Especially, the difference of DOC content between different vegetations was the most significant. The activities of several determined enzymes in the surface soil of secondary Homonoia riparia Lour. Forest, except polyphenol oxidase, were higher than those in native P. australis reed wetland soil.

* 2020-08-09 收稿;2021-03-24 收修改稿.

国家水体污染控制与治理科技重大专项 (2017ZX07603003) 资助.

** E-mail: cmyang@tongji.edu.cn. 
Especially, the invertase activity increased most obviously. However, lakeshore urban green park and artificial grassland showed significantly lower activities of catalase, urease and invertaseas compared with native $P$. australis wetland. Correlation analysis showed that there existed significant relationships between soil enzyme activities except polyphenol oxidase and soil DOC and EOC. Especially, the correlations of invertase activity to the content of DOC reached remarkably significant level with the highest coefficient $(r=0.907)$. Based on the above results, it is concluded that the DOC and invertase as the sensitive indicators, could well characterize the degradation process and ecological restoration effect on lakeshore wetland buffering function due to land use and cover change.

Keywords: Lake Chaohu; lakeshore wetland; land use and cover change; soil dissolved organic carbon; invertase activity

湿地生态系统是陆地上重要的有机碳库, 其不仅储存大量的有机碳, 而且被认为是大气中二氧化碳的 重要碳汇基地, 对减缓全球气候变化具有重要作用 ${ }^{[1]}$. 土壤也是湿地生态系统中极其重要的生态因子,其有 机碳含量显著影响湿地生态系统的环境调节功能. 目前, 人类活动对土壤有机碳的含量造成了消极的影 响 ${ }^{[2]}$, 如土地利用和土地覆盖 ( LUCC) 的改变会导致湿地植物群落发生次生演变以及水文条件的变化,这将 会显著影响湿地土壤碳汇功能, 从而影响整个地球生态系统碳循环 ${ }^{[3]}$. 随着全球气候变暖的加剧以及人类 的不合理利用, 湿地退化严重, 导致土壤中有机碳分解速率加快, 温室效应突显, 对全球气候变化造成重要 的影响 ${ }^{[4]}$. 因此, 开展土壤有机碳特征对湿地土地利用改变的响应过程研究, 不仅有助于科学评价湿地退化 程度, 而且有助于精确估算湿地生态系统碳收支状况, 为准确预测气候变化以及对遭到破坏的湿地土壤生 态功能进行恢复与重建有重要意义 ${ }^{[5]}$.

土壤有机碳库包括易分解和矿化的活性有机碳组分, 其对土壤管理措施响应最为敏感, 也最容易从碳 库中丢失 ${ }^{[6]}$. 土壤有机碳降解过程需要特定功能的胞外酶来协助完成, 而胞外酶通常会受到土壤物理和化 学性质改变的影响 ${ }^{[6]}$, 从而影响到土壤中有机碳的分解和循环过程. Alster 等 ${ }^{[7]}$ 和 $\mathrm{Du}^{\text {等 }}{ }^{[8]}$ 研究认为蔗糖酶 和多酚氧化酶活性与湿地土壤的碳循环有重要关系. 另外, 目前研究表明, 相对于总有机碳而言, 土壤中一 些活性有机碳组分对人类活性干扰响应更为敏感 ${ }^{[9-10]}$. 目前关于土地利用和土地覆盖变化对森林和草地土 壤有机碳组分的影响已有报道, 其机理主要是土地利用和覆盖的变化影响了微生物代谢作用, 从而改变了 土壤有机碳结构的稳定性 ${ }^{[11-12]}$. 但是, 湖滨带湿地土地利用方式改变造成的活性有机碳组分改变及其对土 壤酶活性的影响以及作用机理仍不清晰.

湖滨带是湖泊水陆生态系统间的物流、能流、信息流和生物流热点场所, 发挥着过滤器和屏障作用的缓 冲带功能, 拥有维持陆地和湖泊生态系统平衡稳定的重要作用 ${ }^{[13-14]}$. 但是, 湖滨带湿地作为地球上最为脆弱 的湿地系统之一, 受人类活动影响最为强烈 ${ }^{[15]}$. 巢湖位于安徽省中部, 为我国五大淡水湖之一, 为典型淡水 浅水湖泊, 过去拥有大面积的湖滨带原生芦苇湿地. 由于受到强烈的人为活动干扰, 特别是城镇化的快速发 展, 加上常年高水位运行, 目前巢湖湖滨带原生芦苇面积严重萎缩, 土地利用与覆盖发生明显变化, 造成湖 滨带生态系统功能退化, 大大削弱了湖滨缓冲带对陆源污染的拦截和降解作用, 从而对巢湖水体水质造成 不良影响 ${ }^{[16]}$. 本研究以巢湖湖滨带为研究对象, 通过对不同土地利用和覆盖下湖滨带土壤有机碳组分和酶 活性进行测定, 以阐明湖滨带原生湿地改变后对土壤有机碳组分特征与生化代谢过程的影响, 研究结果将 为揭示湖滨带土壤对土地利用与覆被改变响应的微观机制以及篮选出敏感的表征指标提供理论依据和 方法.

\section{1 研究区域和研究方法}

\section{1 研究区域概况}

巢湖为我国五大淡水湖之一, 湖面积约 $780 \mathrm{~km}^{2}$, 流域面积 $13486 \mathrm{~km}^{2}$. 巢湖东西长 $54.5 \mathrm{~km}$, 南北宽 21 $\mathrm{km}$, 湖岸线长约 $170 \mathrm{~km}$. 巢湖水深 $2 \sim 5 \mathrm{~m}$, 多年平均水深 $2.69 \mathrm{~m}$, 库容为 17.17 亿 $\mathrm{km}^{3}$. 巢湖流域属北热带湿 润季风气候区, 四季分明、气候温和, 年均气温 $15.8^{\circ} \mathrm{C}$, 极端最高气温 $41.1^{\circ} \mathrm{C}$, 极端最低气温 $-20.6^{\circ} \mathrm{C}$, 无霜期 约 $225 \mathrm{~d}$. 流域年均降雨量 $1120.3 \mathrm{~mm}$, 年际变化悬殊. 巢湖北部地貌类型主要为平坦平原、波状平原、浅丘状 平原和丘陵地貌, 受区域地理地质环境、成土条件和成土过程的影响, 主要分布着河流冲积物母质和晚更新 世黄土母质,形成了以黄褐土、水稻土为主要类型的土壤. 区域内分布有大量的湖滨带原生湿地, 其代表性 
植被类型包括芦苇和水柳,这些原生态湖滨带湿地不仅是重要的碳库, 同时对拦截、净化陆源污染、改善巢 湖水环境发挥极其重要作用. 但是, 近几年随着环湖大道的修建和城镇化的快速发展,很多湖滨带原生植被 已经被破坏, 取而代之的是人工景观植被, 包括绿地公园和岸上草原, 从而大大削弱湖滨带的生态和环境 功能.

\section{2 样地设置与样品采集}

本次采样区域位于巢湖北岸的湖滨大道沿线湖岸, 该区域受人类干扰和城镇化影响最大, 本研究区域 所在位置及采样点分布见图 1 所示.

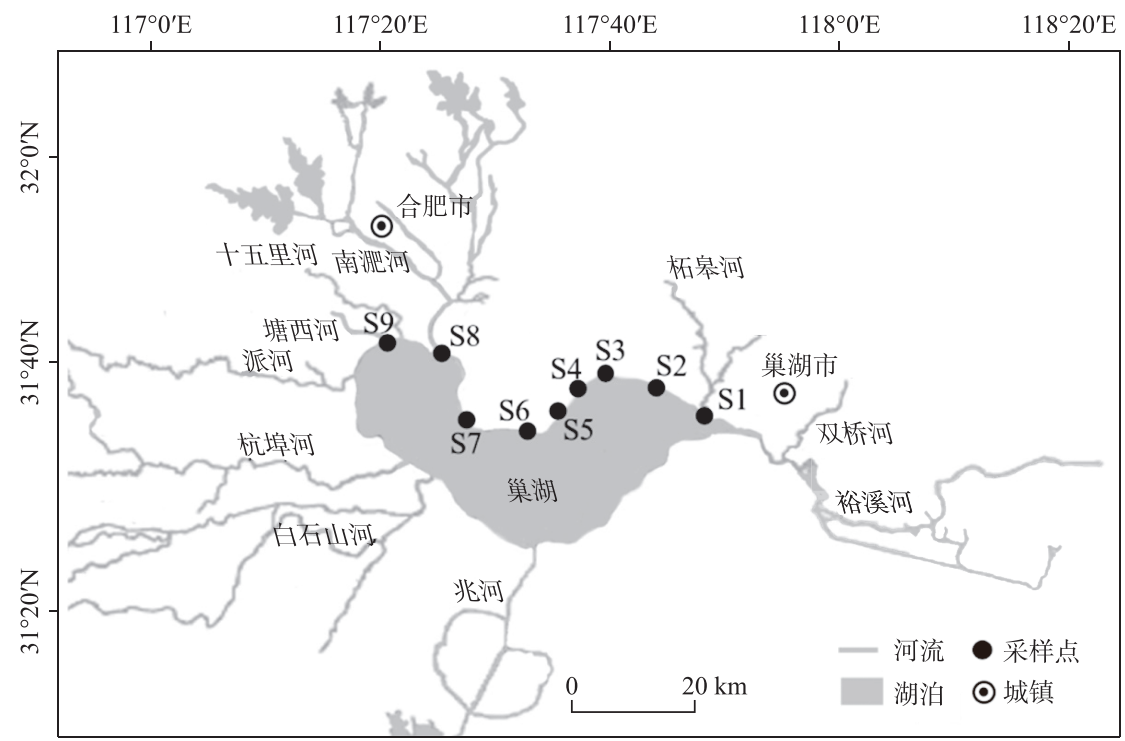

图 1 研究区域及采样点分布

Fig.1 Study area and distribution of sampling sites

根据湖滨带植被类型和受人类活动影响程度共设 9 个采样点, $\mathrm{S} 1$ 为原生芦苇 (Phragmites australis (Cav.) Trin. ex Steud) 湿地, 植被覆盖度高达 70\% 80\%, 面积约为 $2.0 \mathrm{hm}^{2} ; \mathrm{S} 2$ 和 S3 采样点分别位于原生芦 苇湿地破坏后经过 10 20 年种植历史的次生水柳林 (Homonoia riparia Lour.), 林下为杂草, 植被覆盖度 $45 \% \sim 60 \%$, 面积分别约为 2.5 和 $3.1 \mathrm{hm}^{2}$; S4 位于 15 年水柳林和芦苇带混交区,植被覆盖度 40\% 55\% 左

\section{表 1 不同采样点基本信息}

Tab.1 Basic information of different sampling points

\begin{tabular}{clccc}
\hline $\begin{array}{c}\text { 采样 } \\
\text { 点 }\end{array}$ & 土地利用覆盖类型 & $\begin{array}{c}\text { 覆盖度/ } \\
\%\end{array}$ & $\begin{array}{c}\text { 种植 } \\
\text { 年限/a }\end{array}$ & $\begin{array}{c}\text { 常水 } \\
\text { 位/m }\end{array}$ \\
\hline S1 & 原生芦苇湿地 & $70 \sim 80$ & $>30$ & 0.2 \\
S2 & 次生水柳林 & $45 \sim 50$ & 10 & 0.1 \\
S3 & 次生水柳林 & $50 \sim 60$ & 20 & 0.1 \\
S4 & 水柳与芦苇混交区 & $40 \sim 55$ & 15 & 0.1 \\
S5 & 芦苇退化后的荒滩 & 0 & $>15$ & 0.2 \\
S6 & 人工水杉林 & $50 \sim 60$ & 8 & 0.3 \\
S7 & 人工水杉林 & $45 \sim 55$ & 5 & 0.3 \\
S8 & 城市公园绿地 & $30 \sim 40$ & 10 & 0 \\
S9 & 人工草滩 & $35 \sim 40$ & 10 & 0 \\
\hline & & & &
\end{tabular}

右, 面积约为 $1.5 \mathrm{hm}^{2}$; $\mathrm{S} 5$ 为受人类活动干扰和风浪 侵蚀严重的荒滩, 原来也是芦苇湿地, 目前植被平均 覆盖度仅为 $16 \%$ 左右, 面积约为 $1.2 \mathrm{hm}^{2}$; S6 和 S7 分 别为 8 年和 5 年恢复历史的纯人工水杉 (Metasequoia glyptostroboides Hu et Cheng) 林, 植被覆盖度为 45\% $60 \%$, 面积分别约为 1.5 和 $1.7 \mathrm{hm}^{2}$; S8 和 S9 分别为 2010 年左右由退化芦苇湿地构建的城市公园绿地和 人工草滩 (岸上草原), 由于受游客踩踏严重, 植被长 势一般, 平均覆盖度为 $40 \%$ 左右, 但面积较大, 分别 约为 3.5 和 $4.2 \mathrm{hm}^{2}$. 不同采样点基本信息如表 1 所示.

采样时间是 2017 年 3 月 28 日. 在每种湖滨带湿 地类型中选择 3 块 $4 \mathrm{~m} \times 4 \mathrm{~m}$ 的样地, 设定为研究采 样点, 并观测记录地表植被分布、地理位置等相关信 
息,由于采样期间巢湖正处于枯水季节,水位较低,9个采样点所在样地均高出湖水水面,无明显水层. 采用 多点混合法采集 $0 \sim 30 \mathrm{~cm}$ 深度的表层土壤样品. 每个样点采集 $2 \mathrm{~kg}$ 的土样, 取好的土样装人塑料袋中密封 好, 立即放人装有冰块的冷藏箱中保存, 并及时带回实验室进行分析. 称取一半重量的新鲜土样立即分析测 定过氧化氢酶、袮酶、多酚氧化酶、蔗糖酶等酶的活性; 另一半土壤样品经剔除可见的动、植物残体和石块后 进行自然风干、磨细分别过 0.85 和 $0.25 \mathrm{~mm}$ 孔篎, 以测定土壤 $\mathrm{pH}$ 和阳离子交换量 (CEC); 研磨过 $0.15 \mathrm{~mm}$ 孔篮分别测定土壤总有机碳( TOC) 及溶解性有机碳 (DOC)、易氧化有机碳 (EOC) 等活性有机碳组分含量. 每个样品 3 次重复.

\section{3 分析方法}

1.3.1 土壤基本理化指标分析 土壤 $\mathrm{pH}$ 采用 $\mathrm{pH}$ 计测定 (上海雷磁 PHSJ-3F 型), 浸提水土比为 $2.5: 1$; 土壤 容重采用环刀法测定; $\mathrm{CEC}$ 测定采用 $\mathrm{BaCl}_{2}-\mathrm{H}_{2} \mathrm{SO}_{4}$ 强迫交换法: 以 $\mathrm{Ba}^{2+}$ 离子交换沉积物中的各种阳离子, 再 以硫酸将交换到沉积物中的 $\mathrm{Ba}^{2+}$ 沉淀出来, $\mathrm{H}^{+}$被交换到土壤中, 通过滴定剩余硫酸溶液的 $\mathrm{H}^{+}$物质的量计算 CEC 值. 土壤中总氮 ( TN) 含量采用凯氏定氮法测定. 以上指标具体测定方法可参考文献 [17].

土壤 TOC 含量采用总有机碳分析仪法, 使用有固体进样器 ( SSM-5000A) 的总有机碳分析仪 ( TOC-V $\mathrm{CPN}$ ) (日本岛津公司) 进行测定. 土壤 DOC 含量测定: 取 $6.0 \mathrm{~g}$ 过 $0.15 \mathrm{~mm}$ 孔篎的风干土样加人 $50 \mathrm{~mL}$ 离心 管中, 并加人 $25 \mathrm{~mL}$ 蒸馏水, 放人摇床中, 调至摇床速度至 $180 \mathrm{r} / \mathrm{min}$, 振荡 $1 \mathrm{~h}$, 之后放人离心机中, 调至转速 为 $3500 \mathrm{r} / \mathrm{min}$, 离心 $20 \mathrm{~min}$, 将离心好的悬浊液倒人真空抽滤装置中进行抽滤, 使用 $0.45 \mu \mathrm{m}$ 膜过滤, 得到的 上清液即为土壤样品的 DOC 浸提液, 倒人 TOC 仪器专用试剂瓶中, 使用总有机碳分析仪 (TOC-V CPN) 进行

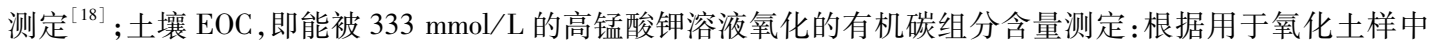
的“易氧化碳”之后的高锰酸钾 (剩液) 的浓度与对照浓度之差来定量土样中易氧化碳消耗高锰酸钾的摩尔 质量, 进而计算每个土壤中的易氧化有机碳的含量, 土壤有机碳氧化量用 $\mathrm{mg} / \mathrm{kg}$ 表示 $\left(1 \mathrm{mmol} \mathrm{KMnO}_{4}\right.$ 氧化 $0.75 \mathrm{mmol} \mathrm{C})^{[19]}$.

1.3.2 土壤酶活性测定 土壤腿酶活性采用静酚蓝比色法 ${ }^{[20]}$; 该方法以尿素为基质, 酶促产物氨与苯酚一次 氯酸钠作用生成蓝色的静酚, 该生成物量与氨浓度呈正比, 腿酶的活性以 $24 \mathrm{~h}$ 后 $1 \mathrm{~g}$ 土壤中产生的 $\mathrm{NH}_{3}-\mathrm{N}$ 质量表示 $(\mathrm{mg} /(\mathrm{g} \cdot 24 \mathrm{~h}))$; 蔗糖酶采用二硝基水杨酸比色法 ${ }^{[18]}$, 其活性以 $24 \mathrm{~h}$ 内 $1 \mathrm{~g}$ 干土生成葡萄糖毫克 数表示 $(\mathrm{mg} /(\mathrm{g} \cdot 24 \mathrm{~h}))$; 多酚氧化酶采用邻苯二酚比色法 ${ }^{[21]}$, 多酚氧化酶的活性以 $2 \mathrm{~h}$ 后 $1 \mathrm{~g}$ 干土样中紫色 没食子素的毫克数表示 $(\mathrm{mg} /(\mathrm{g} \cdot 2 \mathrm{~h}))$; 过氧化氢酶活性采用紫外分光光度法 ${ }^{[22]}$ : 通过加人定量过量的过氧 化氢, 与土壤反应一段时间后, 加人量与剩余之差即为被酶催化反应消耗的过氧化氢, 以此表示酶活性, 单 位为 $\mathrm{mg} /(\mathrm{g} \cdot \mathrm{h})$.

\section{4 数据处理与统计分析}

采用 Excel 2010 和 SPSS 19.0 统计软件对实验数据 进行处理,所有实验数据通过 ANOVA 变异分析程序进 行统计分析. 采用邓肯新复检验法 (Duncan'newmultiple range test) 对巢湖湖滨带不同采样点土壤有机碳组分和 酶活性进行差异显著性分析, 在 $P<0.05$ 的概率水平视 为显著. 采用 Pearson 相关性分析评价湖滨带湿地土壤 有机碳组分与酶活性之间的相关性.

\section{2 结果与分析}

\section{1 不同采样点土壤基本理化指标差异}

由表 2 可以明显看出,除土壤 $\mathrm{pH}$ 外, 不同采样点土 壤容重和阳离子交换量 $($ CEC $)$ 均存在明显差异 $(P<$ $0.05)$. 土壤容重以原生芦苇湖滨带湿地土壤最低, 植被 破坏后裸露并出现沙化的 S5 点最高, 基本上呈现出受 人为影响程度越高, 其湖滨带土壤容重也越高的趋势.
表 2 不同采样点土壤主要理化性质"

Tab.2 Major soil physiochemical properties from different sampling sites

\begin{tabular}{cccc}
\hline $\begin{array}{c}\text { 采 } \\
\text { 样点 }\end{array}$ & $\begin{array}{c}\text { 阳离子交换量/ } \\
(\mathrm{cmol} / \mathrm{kg})\end{array}$ & $\begin{array}{c}\mathrm{pH} \\
(\text { 水:土 }=2.5: 1)\end{array}$ & $\begin{array}{c}\text { 土壤容重/ } \\
\left(\mathrm{g} / \mathrm{cm}^{3}\right)\end{array}$ \\
\hline $\mathrm{S} 1$ & $21.1 \pm 3.78^{\mathrm{a}}$ & $6.35 \pm 0.89^{\mathrm{c}}$ & $1.06 \pm 0.15^{\mathrm{d}}$ \\
$\mathrm{S} 2$ & $16.2 \pm 2.56^{\mathrm{cd}}$ & $6.45 \pm 1.12^{\mathrm{c}}$ & $1.09 \pm 0.17^{\mathrm{d}}$ \\
$\mathrm{S} 3$ & $17.9 \pm 2.8^{\mathrm{bc}}$ & $6.73 \pm 1.31^{\mathrm{a}}$ & $1.03 \pm 0.20^{\mathrm{d}}$ \\
$\mathrm{S} 4$ & $18.8 \pm 4.12^{\mathrm{b}}$ & $6.75 \pm 0.96^{\mathrm{a}}$ & $1.05 \pm 0.19^{\mathrm{d}}$ \\
$\mathrm{S} 5$ & $9.07 \pm 2.01^{\mathrm{h}}$ & $6.01 \pm 1.33^{\mathrm{d}}$ & $1.21 \pm 0.33^{\mathrm{a}}$ \\
$\mathrm{S} 6$ & $15.1 \pm 2.78^{\mathrm{de}}$ & $6.59 \pm 1.09^{\mathrm{b}}$ & $1.11 \pm 0.28^{\mathrm{c}}$ \\
$\mathrm{S} 7$ & $14.0 \pm 2.39^{\mathrm{ef}}$ & $6.45 \pm 1.25^{\mathrm{c}}$ & $1.14 \pm 0.16^{\mathrm{b}}$ \\
$\mathrm{S} 8$ & $13.2 \pm 3.16^{\mathrm{fg}}$ & $6.43 \pm 1.16^{\mathrm{c}}$ & $1.12 \pm 0.22^{\mathrm{bc}}$ \\
$\mathrm{S} 9$ & $12.1 \pm 2.53^{\mathrm{g}}$ & $6.73 \pm 1.22^{\mathrm{a}}$ & $1.15 \pm 0.23^{\mathrm{b}}$ \\
\hline
\end{tabular}

*1) 表中数据为平均值 \pm 标准误;2) 同一列数据后面 上标不同小写字母表明 $P<0.05$ 水平显著差异. 
CEC 是表征土壤具有缓冲性能的重要指标, 特别是对于湖滨带湿地来说, 该指标可以有效表征湖滨带缓冲 带对陆源污染物的吸附作用. 从表 2 可以明显看出, 随着湖滨带土地利用和覆被的变化以及人工干扰强度 的增加, 土壤 CEC 大小均呈现不同程度下降的趋势, 从而会导致湖滨带湿地缓冲功能减弱.

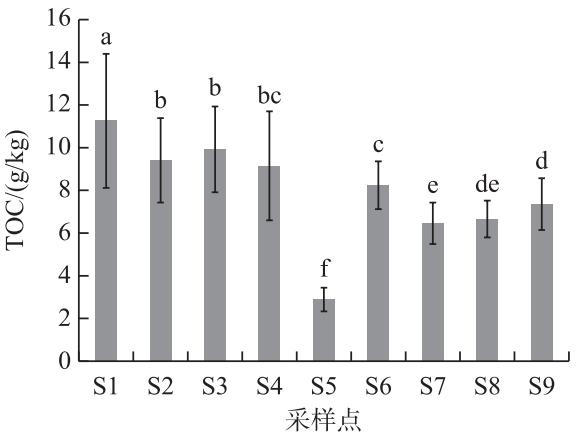

图 2 不同采样点土壤总有机碳含量比较 (不同小写字母表示差异显著 $(P<0.05)$, 下同)

Fig.2 Comparison of soil total organic carbon (TOC) content from different sampling sites

\section{2 不同采样点土壤 TOC 含量}

巢湖北岸湖滨带不同土地利用和覆被下各采样 点土壤样品 TOC 含量变化范围为 $7.88 \sim 11.2 \mathrm{~g} / \mathrm{kg}$, 平 均含量为 $9.12 \mathrm{~g} / \mathrm{kg}$ (图 2). 不同采样点的土壤 TOC 含量存在明显的差异 $(P<0.05)$, 其中原生芦苇湿地 (S1) 土壤 TOC 含量最高, 高达 $11.2 \mathrm{~g} / \mathrm{kg}$, 由芦苇湿 地改种的次生水柳林 (S2 和 S3) 土壤平均 TOC 含量 次之 $(10.3 \mathrm{~g} / \mathrm{kg})$, 而芦苇群落消失后形成的荒滩土 壤 TOC 含量最低,仅为 $2.88 \mathrm{~g} / \mathrm{kg}$. S6 S9 分别为原生 芦苇湿地破坏后人工种植 $8 \mathrm{a}$ 的水杉林、 $5 \mathrm{a}$ 的水杉 林、绿地公园和人工草滩,其土壤 TOC 含量明显低于 次生的水柳林和原生的芦苇湿地土壤, 但显著高于 S5 采样点 $(P<0.05)$. 通过比较还发现, 人工水杉林 种植年限越长, TOC 含量增加越明显. 由此可见, 对 于受人为破坏的湖滨带湿地, 适当进行植被修复, 可 以对土壤有机碳起到一定的恢复作用,但是很难恢复到原生湿地土壤有机碳水平.

\section{3 不同采样点土壤活性有机碳含量比较}

湖滨带表层土壤活性有机碳组分, 即 DOC 和 EOC 含量变化范围分别为 $150 \sim 370 \mathrm{mg} / \mathrm{kg}$ 和 $1.7 \sim 5.2 \mathrm{~g} /$ $\mathrm{kg}$ (图 3). 从图 3 可以看出, 与 TOC 相似, 不同采样点土壤中活性有机碳组分 (DOC 和 EOC) 含量差异也非 常明显,但与 TOC 含量变化趋势不完全一致. 另外, 不同采样点表层土壤 DOC 和 EOC 的差异明显高于 TOC. DOC 含量最高值出现在植被恢复较好的次生水柳林湿地, 最低出现在土壤裸露程度较高的 S5 点, 说明 DOC 可以很好反映出湖滨带湿地植被覆盖程度和受人类干扰程度, 可作为表征湖滨带湿地退化程度的敏感性指 标. 从图 4 中还可以看出, 同样是活性有机碳组分, EOC 含量在不同采样点的变化趋势与 DOC 和 TOC 略有 不同, 其最高值出现在天然芦苇和水柳混合带湿地林, 但最低值却出现在 8 年种植历史的人工水杉林湿地. 位于植被裸露的荒滩土壤 EOC 含量却明显高于人工水杉林湿地 EOC 含量. 而位于滨湖城市公园绿地和人 工草地的 S8 和 S9 样点土壤 EOC 含量却略高于原生芦苇湿地, 与实际湖滨带植被覆盖度和受人为活动干扰 程度吻合度不及 DOC.
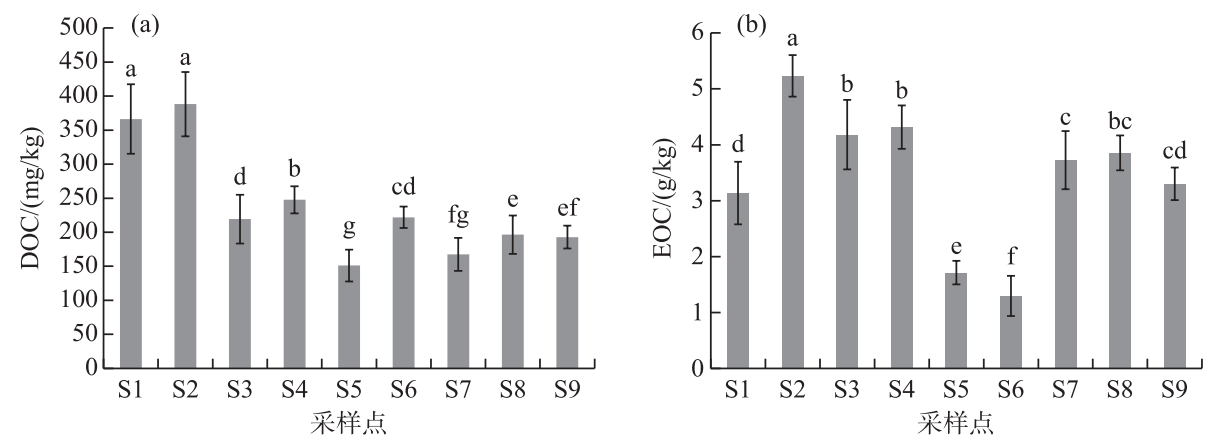

图 3 不同采样点土壤溶解性有机碳 (a) 与易氧化有机碳 (b) 含量比较

Fig.3 Comparisons of soil dissolved organic carbon (a) and easily-oxidation organic carbon (b) contents from different sampling sites 
溶解性有机碳占总有机碳的比值 (DOC/TOC) 也可以 反映土壤有机碳的总体活性和转换效率. 从图 4 可看到, 位于水柳林和芦苇带混合区 S3 的 DOC/TOC 比值最低, 说明湿地土壤有机碳易分解组分所占比例较小, 有机碳较 为稳定, 利于土壤有机碳的累积. 而在所有采样点中, 位 于植被稀少、且沙化严重的 S5 采样点表层土壤 DOC/TOC 比值却为最高.

\section{4 不同采样点土壤酶活性比较}

巢湖湖滨带不同采样点土壤中与碳、氮代谢过程相关 的几种关键酶活性也存在显著差异 (图 5). 过氧化氢酶和 蔗糖酶活性以种植 20 年历史的次生水柳树林采样点 S3 为最高, 种植 10 年历史的次生水柳树林采样点 S2 和原生 芦苇湿地次之, 而植被稀疏并侵蚀沙化较为严重的 S5 采 样点过氧化氢酶和蔗糖酶活性均为最低. 尿酶活性则以 S2 和 S3 采样点为最高, 说明芦苇湿地变为次生水柳林有利

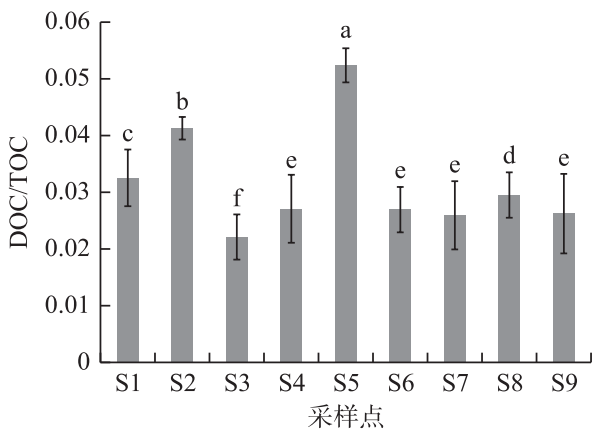

图 4 不同采样点土壤中溶解性 有机碳与总有机碳比值分布

Fig.4 Ratio of soil dissolved organic carbon to total organic carbon ( DOC/TOC)

from different sampling sites 于土壤中腿酶活性的提升. 不同采样点多酚氧化酶活性变 化则与其它 3 种酶呈现出几乎相反的规律, 其活性最高土壤位于 S5 采样点, 原生植被湖滨带和人工恢复湖 滨带土壤多酚氧化酶活性反而皆较低, 相关机理还有待于进一步研究. 相对于植被稀疏的 S5 采样点, S6 S8 采样点由于实施了人工林 (草) 种植和恢复过程, 其湖滨带土壤酶活性具有明显的提升作用 (图 6), 特别是 腿酶和蔗糖酶活性增加效果更为明显. 与 $\mathrm{S} 5$ 相比较, S6 S8 采样点土壤腿酶和蔗糖酶活性平均值分别增加 了 $78.6 \%$ 和 $89.4 \%$. 由此表明, 对遭人为破坏后的原生芦苇湿地湖滨带进行植被生态修复, 可以逐步恢复湖 滨带土壤生化和生态功能.
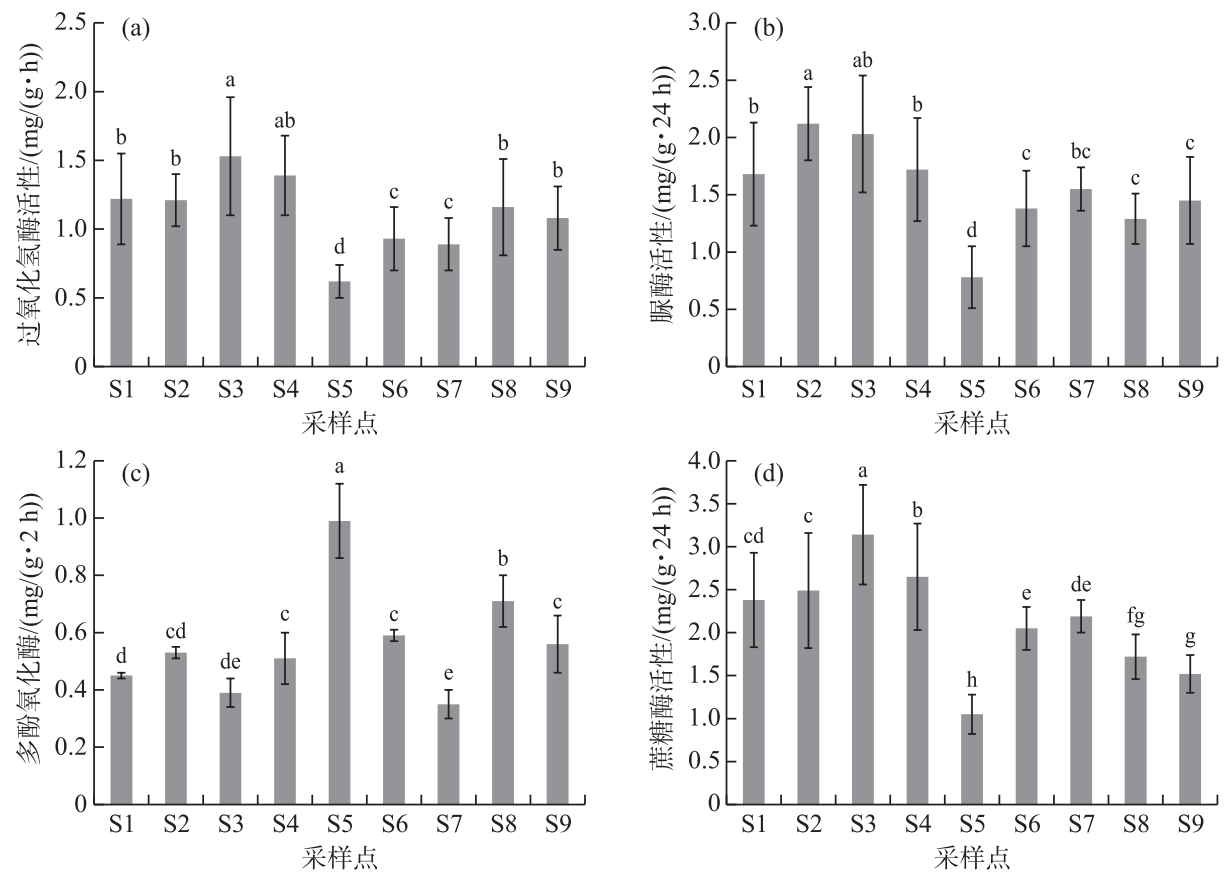

图 5 不同采样点土壤过氧化氢酶 (a)、沓酶 (b)、多酚氧化酶 (c) 和蔗糖酶 (d) 活性比较

Fig.5 Comparisons of soil enzymatic activities of catalase (a), urease (b), polyphenol oxidase (c), and invertase $(d)$ from different sampling sites 
表 3 为巢湖湖滨带不同采样点几种关键性酶活性与土壤有机碳组分及主要理化指标之间的相关性分 析结果. 从表 3 中可以看出, 过氧化氢酶、豚酶和多酚氧化酶活性与土壤 CEC 和 $\mathrm{pH}$ 相关性皆不显著 $(P>$ $0.01)$, 蔗糖酶活性与 CEC 呈显著正相关 $(P<0.05)$, 但是与 $\mathrm{pH}$ 关系不显著 $(P>0.05)$. 除多酚氧化酶外, 其 他几种酶的活性与土壤总氮 (TN) 含量到显著水平, 其中俆酶活性与 TN 含量相关系数为 0.893 , 达到极显著 水平 $(P<0.01)$. 所测定的几种土壤酶活性与土壤有机碳组分之间呈现不同程度的相关性, 其中过氧化氢酶、 腿酶和蔗糖酶活性与 TOC 含量的相关性均达到显著水平 $(P<0.05)$, 而与活性有机碳组分 EOC 和 DOC 含量 的相关性达到极显著水平 $(P<0.01)$. 蔗糖酶活性与 DOC 含量的变化趋势符合程度极高, 当蔗糖酶活性达到 最大值 $3.14 \mathrm{mg} /(\mathrm{g} \cdot 24 \mathrm{~h})$ 时, 土壤的 DOC 含量随之达到接近 $1 \%$ 的高水平, 相关系数达到 0.907 . 与其他几种 酶相反, 多酚氧化酶与土壤有机碳组分呈负相关性, 但只与 TOC 含量的相关性达到显著水平 $(P<0.05)$, 与 EOC 和 DOC 含量之间负相关性不显著 $(P>0.01)$. 腿酶与 TN 含量的相关系数为 0.893 , 腿酶与 TN 含量存在 不可分割的联系.

表 3 湖滨带土壤关键酶活性与土壤理化性质及土壤有机碳含量相关系数

Tab.3 Correlation coefficents between soil enzymatic activities and soil physiochemical properties, soil carbon fractions

\begin{tabular}{ccccccc}
\hline 酶活性 & CEC & $\mathrm{pH}$ & $\mathrm{TOC}$ & $\mathrm{TN}$ & $\mathrm{EOC}$ & $\mathrm{DOC}$ \\
\hline 过氧化氢酶活性 & 0.503 & -0.218 & $0.858^{*}$ & $0.772^{*}$ & $0.881^{* *}$ & $0.901^{* *}$ \\
脲酶活性 & 0.501 & -0.252 & $0.758^{*}$ & $0.893^{* *}$ & $0.722^{*}$ & $0.860^{*}$ \\
多酚氧化酶活性 & -0.462 & 0.274 & $-0.637^{*}$ & -0.544 & -0.362 & -0.486 \\
蔗糖酶活性 & $0.633^{*}$ & -0.281 & $0.891^{* *}$ & $0.647^{*}$ & $0.901^{* *}$ & $0.907^{* *}$ \\
\hline
\end{tabular}

* 和 $* *$ 分别表示在 $P<0.05$ 和 $P<0.01$ 水平上达到显著相关性.

\section{3 讨论}

\section{1 土地利用及覆被改变对湖滨带土壤碳截存能力影响及其环境效应}

研究表明,湿地土壤 TOC 含量主要取决于植被积累和分解速率, 当植被的积累量大于分解量时土壤 TOC 开始进行累积 ${ }^{[23]}$. 因此, 土壤 TOC 含量及储存主要受植被类型与覆盖度影响,夏品华等 ${ }^{[24]}$ 对贵州高原 草海湿地的研究结果表明, 不同湿地植物类型及其退化程度下土壤 TOC 含量差异明显. 本研究结果也表明, 巢湖湖滨带不同土地利用方式与覆盖度下土壤 TOC 含量差异显著. 湖滨带原生芦苇湿地由于地上部分生物 量较大, 有机质返还率较高, 加上地势较低, 长期或周期性淹水, 有机质分解速率较低, 导致土壤中有机质不 断积累, TOC 含量在所有采样点为最高. 而巢湖湖滨带原生芦苇湿地退化后变为植被稀疏的荒滩后, 土壤 TOC 含量迅速下降, 如 S5 采样点 TOC 含量为 $2.88 \mathrm{~g} / \mathrm{kg}$, 约为原生芦苇湿地土壤的 $1 / 4$. 原生芦苇湿地退化 后改种水柳或通过其他人工植被恢复后土壤 TOC 含量出现不同程度的增加. 通过比较还发现, 人工种植年 限越长, TOC 含量增加越明显. 由此可见, 对于受人为破坏的湖滨带湿地, 适当进行植被修复, 可以提升土壤 碳汇能力, 但是很难恢复到原生湿地土壤有机碳水平. 而受人类活动干扰较大的湖滨城市绿地和人工草滩 对土壤有机碳的截存能力会产生不利影响.

土地利用与覆被变化所导致的湿地土壤碳截存能力及稳定性下降将会引发不良的环境效应 ${ }^{[25]}$. 湿地 土地利用方式变化后, 水文条件发生改变, 加上土壤扰动比较频繁, 土壤呼吸作用增加, 从而加速了 TOC 的 分解消耗 ${ }^{[26]}$, 并成为温室气体排放的重要策源地. 湖滨带原生芦苇湿地被人为开发破坏之后, 脱离了原有 的植被环境, 土壤中有机碳的稳定性大大降低, 其损耗的速率也将加快 ${ }^{[27]}$, 使得湖滨带湿地由 “碳汇” 变成 “碳源”, 对减缓全球气候变化产生不利影响. 另外, 湿地土壤有机碳是衡量湿地缓冲性能的重要指标, 土地 利用和覆盖的改变所导致的湖滨带有机碳含量的下降和微团聚体的缺失将大大降低了湖滨带湿地的缓冲 性能, 特别是削弱了湖滨带对面源污染的拦截、净化能力, 从而会影响湖体水质 ${ }^{[28-29]}$. 有研究表明, 湖滨缓冲 带保留越完整, 土壤 TOC 含量越高, 土壤微团聚体也越丰富, 从而大大提高土壤对陆源污染物的吸附能力, 这对提升湖滨带生态环境功能具有重要意义 ${ }^{[30-31]}$. 


\section{2 湖滨带原生芦苇湿地改变后对土壤活性有机碳组分的影响}

目前有研究表明, 与 TOC 含量相比较, 土壤中分子量较小、易被微生物分解的活性有机碳组分, 如易氧 化有机碳 (EOC)、溶解性有机碳 (DOC) 和轻组分有机碳 ( LFOC) 等对土地利用及覆盖变化响应更为敏 感 ${ }^{[32-33]}$. 本研究结果也表明, 巢湖湖滨带不同采样点土壤中 EOC、DOC 含量差异明显高于 TOC 在不同采样 点之间的差异, 特别是土壤 DOC 含量受湖滨带土地利用与覆盖变化的影响最为显著. 巢湖湖滨带原生芦苇 湿地虽然 TOC 含量最高, 但是土壤活性有机碳组分 EOC 和 DOC 最高值却出现次生水柳林样地, 主要原因 可能是次生水柳林土壤本身总有机质较高, 同时由于次生水柳林地势较高, 每年大部分时间露在外面, 积水 极少, 土壤平均温度较高, 土壤中好氧微生物代谢作用较强 ${ }^{[34]}$, 使得原来被截存在芦苇湿地土壤中大分子腐 殖质被分解成小分子的活性有机碳组分. 但是, 植被稀疏的荒滩由于地上部分归还率较低, 同时缺乏植被保 护, 土壤平均温度也会明显上升, 从而导致微生物对有机碳分解作用加强, 分解后形成的活性有机碳组分也 会迅速再次分解成 $\mathrm{CO}_{2}$ 和水 ${ }^{[35]}$, 从而导致其土壤中总有机碳和活性有机碳组分皆很低. DOC/TOC 是衡量土 壤中有机碳稳定性重要指标 ${ }^{[36]}$. 目前的研究表明, 受人类活动干扰程度越高, 湖滨带土壤中的 DOC/TOC 值 也越高, 特别是位于芦苇湿地破坏后的荒滩 S5 采样点, DOC/TOC 值最高, 这也进一步验证了巢湖湖滨带植 被破坏后会明显降低土壤有机碳库的稳定性,并造成活性有机碳分解加速和土壤碳库的亏损 ${ }^{[37-38]}$.

\section{3 湖滨带土壤酶活性及其与土壤有机碳组分相互作用机制}

湿地土壤酶活性是评价湿地生态功能的一项重要指标 ${ }^{[39]}$. 研究表明, 湿地土壤中酶的活性对土地利用 和覆盖变化的响应也非常敏感 ${ }^{[40-41]}$. 本研究结果也表明, 巢湖湖滨带不同土地利用与覆盖方式下土壤几种 关键酶活性差异非常显著. 除多酚氧化酶外,原生芦苇湿地和次生水柳林及其混交区域土壤酶活性普遍较 高, 而荒滩及受人为活动干扰的城市绿地及人工草地土壤酶活性均出现不同程度的下降. 原生芦苇湿地被 破坏后通过水柳种植与生态恢复可以显著提高土壤中酶的活性, 从而可以提升土壤生态功能. 受人类活动 干扰较小的原生芦苇湿地和次生水柳林及其混交区域植物生长较好, 根系分泌物较多, 土壤碳源, 特别是易 被微生物利用活性碳源较为丰富, 微生物数量及活性也较高, 因此酶活性普遍较高. 而荒滩及受人为活动干 扰的城市绿地及人工草地植被覆盖度较差, 调落物归还率较低, 土壤碳源数量及质量较差, 微生物数量及代 谢活性也较低. 土壤中酶主要来自微生物代谢分泌作用, 其活性也必将会受到土壤有机碳数量及质量的影 响 ${ }^{[39-40]}$. 而活性有机碳, 特别是 DOC 是微生物代谢的主要碳源, 其含量大小必将影响土壤酶的活性. 目前的 研究表明, 巢湖湖滨带土壤中几种酶的活性与土壤有机碳, 特别是活性有机碳组分相关性显著. 同时, 土壤 中有机碳转化和分解过程也受到相关功能性酶活性的影响. 过氧化氢酶活性的上升会导致土壤微生物细胞 膜的破坏程度下降, 对于有机物料的利用效率就能维持在较高水平, 这样就增强了土壤的碳汇能力, 从而使 TOC、DOC、EOC 的含量都保持在较高水平. 有研究认为, 多酚化合物会在多酚氧化酶的活性受抑制时进行 累积, 而酚类物质可以抑制多种水解酶的作用, 如 $\beta$-葡萄糖苷酶、磷酸酶和硫酸酯酶等, 多酚氧化酶通过将 土壤中的芳香族化合物氧化成醌, 进而由醌与土壤中的蛋白质、氨基酸、糖类等进行反应 ${ }^{[42]}$, 消耗土壤中的 有机质, 使得其含量降低. 多酚氧化酶的活性提高会造成土壤有机质, 特别是活性有机碳组分急剧氧化分 解, 降低了土壤碳储存能力, 也会削弱湖滨带的生态缓冲能力.

蔗糖酶对于蔗糖分解的催化作用具有专一性 ${ }^{[43]}$. 蔗糖分解后形成的果糖和葡萄糖是土壤植物与微生 物的重要营养物质. 因此, 蔗糖在土壤总有机碳含量之中占据重要地位, 可以通过蔗糖酶活性来表征土壤有 机碳组分的变化. 目前的研究也表明,巢湖湖滨带不同采样点土壤蔗糖酶活性与 EOC 和 DOC 两种活性有机 碳组分含量的相关性达到极显著水平. 巢湖湖滨带不同采样点蔗糖酶活性变化规律与植被覆盖度吻合程度 也较好, 特别是与人为活动干扰强度关系较为紧密, 可作为今后表征湖滨带受土地利用与覆被变化影响下 土壤有机碳动态变化和生态退化程度较为敏感的指标.

\section{4 结论}

1) 巢湖湖滨带不同土地利用和覆被下土壤有机碳组分差异显著, 其中以原生芦苇湿地 TOC 含量最高. 湖滨带 10 20 年种植历史的次生水柳林湿地土壤 DOC 和 EOC 含量为最高, 其次为原生芦苇湿地; 植被破坏 严重的湖滨带荒滩土壤 TOC 和活性有机碳 (DOC 和 EOC) 含量均为最低. 原生芦苇湿地变为人工植被后, 土 
壤中有机碳的稳定性降低, 土壤固碳能力被削弱.

2) 巢湖湖滨带不同采样点土壤中 4 种关键性酶活性在存在显著差异, 过氧化氢酶、䐂酶和蔗糖酶均以 受人类活动干扰较小的原生芦苇湿地和次生水柳林及其混交区域土壤酶活性普遍较高, 而以植被退化严重 的荒滩土壤酶活性为最低. 几种酶活性与土壤活性有机碳组分之间呈现显著的相关性, 特别是蔗糖酶活性 与 DOC 和 EOC 含量的相关性均达到极显著水平.

3 ) 湖滨带原生芦苇被破坏后通过适当的植被恢复, 可以显著增加土壤活性有机碳库, 并增强湖滨带生 化代谢过程和生态缓冲功能. 土壤 DOC 和蔗糖酶 2 个指标对植被类型、覆盖度以及人类活动响应较为敏感, 可以作为表征湖滨带湿地土地利用与覆被改变所带来的土壤微观变化和生态功能退化的敏感性指标.

\section{5 参考文献}

[ 1 ] Yu JB, Dong HF, Li YZ et al. Spatiotemporal distribution characteristics of soil organic carbon in newborn coastal wetlands of the Yellow River Delta estuary. CLEAN-Soil, Air, Water, 2014, 42(3) : 311-318. DOI: 10.1002/clen.201100511.

[ 2 ] Xiong X, Grunwald S, Myers DB et al. Interaction effects of climate and land use/land cover change on soil organic carbon sequestration. Science of the Total Environment, 2014, 493: 974-982. DOI: 10.1016/j.scitotenv.2014.06.088.

[ 3 ] Mao DH, Wang ZM, Li L et al. Soil organic carbon in the Sanjiang Plain of China: Storage, distribution and controlling factors. Biogeosciences, 2015, 12(6) : 1635-1645. DOI: 10.5194/bg-12-1635-2015.

[ 4 ] Morrissey EM, Berrier DJ, Neubauer SC et al. Using microbial communities and extracellular enzymes to link soil organic matter characteristics to greenhouse gas production in a tidal freshwater wetland. Biogeochemistry, 2014, 117(2/3) : 473490. DOI: $10.1007 / \mathrm{s} 10533-013-9894-5$.

[ 5 ] Ausseil AGE, Jamali H, Clarkson BR et al. Soil carbon stocks in wetlands of New Zealand and impact of land conversion since European settlement. Wetlands Ecology and Management, 2015, 23 ( 5 ) : 947-961. DOI: 10.1007/s11273-015$9432-4$.

[ 6 ] Kim H. A review of factors that regulate extracellular enzyme activity in wetland soils. The Korean Journal of Microbiology, 2015, 51(2) : 97-107. DOI: 10.7845/kjm.2015.4087.

[ 7 ] Alster CJ, German DP, Lu Y et al. Microbial enzymatic responses to drought and to nitrogen addition in a southern California grassland. Soil Biology and Biochemistry, 2013, 64: 68-79. DOI: 10.1016/j.soilbio.2013.03.034.

[ 8 ] Du YH, Guo P, Liu JQ et al. Different types of nitrogen deposition show variable effects on the soil carbon cycle process of temperate forests. Global Change Biology, 2014, 20(10) : 3222-3228. DOI: 10.1111/gcb.12555.

[ 9 ] Yang CM, Yang LZ, Ouyang Z. Organic carbon and its fractions in paddy soil as affected by different nutrient and water regimes. Geoderma, 2005, 124(1/2) : 133-142. DOI: 10.1016/j.geoderma.2004.04.008.

[10] Zhang SJ, Xiang WH, Sun WJ et al. Effects of land use on soil readily oxidized carbon and carbon management index in hilly region of central Hunan Province. Ecology and Environmental Sciences, 2016, 25(6) : 911-919. [张仕吉, 项文化, 孙伟军等. 中亚热带土地利用方式对土壤易氧化有机碳及碳库管理指数的影响. 生态环境学报, 2016, 25(6): 911-919.]

[11] Haghverdi K, Kooch Y. Soil carbon and nitrogen fractions in response to land use/cover changes. Acta Oecologica, 2020, 109: 103659. DOI: 10.1016/j.actao.2020.103659.

[12] Ren CJ, Wang T, Xu YD et al. Differential soil microbial community responses to the linkage of soil organic carbon fractions with respiration across land-use changes. Forest Ecology and Management, 2018, 409: 170-178. DOI: 10.1016/j. foreco.2017.11.011.

[13] Ye C, Li CH, Wu L et al. Ecological degradation of lake littoral zone and interaction effects with human activities. Research of Environmental Sciences, 2015, 28(3): 401-407. [叶春, 李春华, 吴蕾等. 湖滨带生态退化及其与人类活动 的相互作用. 环境科学研究, 2015, 28(3): 401-407.]

[14] Hu XZ, Xu QJ, Jiang LJ et al. A preliminary study on demarcation limits of lake buffer zones: A case study of Lake Taihu. J Lake Sci, 2011, 23(5): 719-724. DOI: 10.18307/2011.0508. [胡小贞, 许秋瑾, 蒋丽佳等. 湖泊缓冲带范围划定 的初步研究——太湖为例. 湖泊科学, 2011, 23(5): 719-724.]

[15] Fergus CE, Lapierre JF, Oliver SK et al. The freshwater landscape: Lake, wetland, and stream abundance and connectivity at macroscales. Ecosphere, 2017, 8(8): e01911. DOI: 10.1002/ecs2.1911. 
[16] Kuang W, Rui M, Zhang YH et al. Effect of nitrogen and phosphorus on rainstorm runoff reduction cut from ecological restoration engineering of Chaohu lakeside zone. Resources and Environment in the Yangtze Basin, 2015, 24 (11): 19061912. [匡武, 芮明, 张彦辉等. 巢湖湖滨带生态恢复工程对暴雨径流氮磷削减效果研究. 长江流域资源与环境, 2015, 24(11) : 1906-1912.]

[17] Lu RK ed. Analytical methods of soil agrochemistry. Beijing: China Agricultural Science and Technology Press, 1999. [鲁 如坤. 土壤农业化学分析方法. 北京: 中国农业科技出版社, 1999.]

[18] Huo LL, Zou YC, Guojia W et al. Effect of reclamation on the vertical distribution of SOC and retention of DOC. Environmental Science, 2013, 34(1) : 283-287. DOI: 10.13227/j.hjkx.2013.01.015. [霍莉莉, 邹元春, 郭佳伟等. 乍殖对湿 地土壤有机碳垂直分布及可溶性有机碳截留的影响. 环境科学, 2013, 34(1) : 283-287.]

[19] Blair GJ, Lefory RD. Soil C fractions based on their degree of oxidation and the development of a C management index for agricultural system. Australian Journal of Agricultural Research, 1995, 46:1459-1466.

[20] Guan SY ed. Soil enzyme and its research methods. Beijing: Agricultural Press, 1986: 108-111. [关松荫. 土壤酶及其研 究法. 北京: 农业出版社, 1986: 108-111.]

[21] Hao JC, Wu YY, Lian B et al. Properties of polyphenol oxidase in soil and its significance. Chinese Journal of Soil Science, 2006, 37(3) : 470-474. [ 郝建朝, 吴沿友, 连宾等. 土壤多酚氧化酶性质研究及意义. 土壤通报, 2006, 37 (3) : 470-474.]

[22] Yang LF, Zeng Q, Li HB et al. Measurement of catalase activity in soil by ultraviolet spectrophotometry. Chinese Journal of Soil Science, 2011, 42(1) : 207-210. [杨兰芳, 曾巧, 李海波等. 紫外分光光度法测定土壤过氧化氢酶活性. 土壤 通报, 2011, 42(1): 207-210.]

[23] Sanders LM, Taffs K, Stokes D et al. Historic carbon burial spike in an Amazon floodplain lake linked to riparian deforestation near Santarém, Brazil. Biogeosciences, 2018, 15(2) : 447-455. DOI: 10.5194/bg-15-447-2018.

[24] Xia PH, Yu LF, Kou YZ et al. Distribution characteristics of soil organic carbon and its relationship with enzyme activity in the Caohai wetland of the Guizhou Plateau. Acta Scientiae Circumstantiae, 2017, 37(4) : 1479-1485. DOI: 10.13671/ j.hjkxxb.2016.0129. [夏品华, 喻理飞, 寇永珍等. 贵州高原草海湿地土壤有机碳分布特征及其与酶活性的关系. 环境科学学报, 2017, 37(4): 1479-1485.]

[25] Wu QB, Wang XK, Guo R. Soil organic carbon stability and influencing factors. Chinese Journal of Soil Science, 2005,36 (5)：743-747. [ 吴庆标, 王效科, 郭然. 土壤有机碳稳定性及其影响因素. 土壤通报, 2005, 36 (5) : 743-747.]

[26] Waters MN, Kenney WF, Brenner M et al. Organic carbon sequestration in sediments of subtropical Florida lakes. PLoS One, 2019, 14(12) : e0226273. DOI: 10.1371/journal.pone.0226273.

[27] Chen FX, Lu SY, Hu XZ et al. Multi-dimensional habitat vegetation restoration mode for lake riparian zone, Taihu, China. Ecological Engineering, 2019, 134: 56-64. DOI: 10.1016/j.ecoleng.2019.05.002.

[28] Xu QY, Wang P, Wang T et al. Investigation of the impacts of land use structure and landscape pattern on water quality in the Ganjiang River, Lake Poyang Basin. J Lake Sci, 2020, 32(4) : 1008-1019. DOI: 10.18307/2020.0410. [徐启渝, 王鹏, 王涛等. 土地利用结构与景观格局对鄱阳湖流域赣江水质的影响. 湖泊科学, 2020, 32(4) : 1008-1019.]

[29] Xiong C, Hoyer MV. Influence of land use and rainfall variability on nutrient concentrations in Florida Lakes. Lake and Reservoir Management, 2019, 35(1) : 25-37. DOI: 10.1080/10402381.2018.1511659.

[30] Wu JQ, Huang SF, Wu J et al. Pollutant removal efficiency of sward buffers to runoff and the correlation with biomass. $J$ Lake Sci, 2008, 20(6) : 761-765. DOI: 10.18307/2008.06.010. [吴建强, 黄沈发, 吴健等. 缓冲带径流污染物净化 效果研究及其与草皮生物量的相关性. 湖泊科学, 2008, 20(6) : 761-765.]

[31] Li CH, Wang YK, Ye C et al. A proposed delineation method for lake buffer zones in watersheds dominated by non-point source pollution. Science of the Total Environment, 2019, 660: 32-39. DOI: 10.1016/j.scitotenv.2018.12.468.

[32] Lin XD, Qi ZP, Tang SM et al. Oxidizable organic carbon and light fraction organic carbon of artificial plantation land and artificial grassland in Hainan Province. Chinese Journal of Tropical Crops, 2012, 33(1) : 171-177. [林晓东, 漆智平, 唐 树梅等. 海南人工林地、人工草地土壤易氧化有机碳和轻组碳含量初探. 热带作物学报, 2012, 33(1): 171-177.]

[33] Tirol-Padre A, Ladha JK. Assessing the reliability of permanganate-oxidizable carbon as an index of soil labile carbon. Soil Science Society of America Journal, 2004, 68(3) : 969-978. DOI: 10.2136/sssaj2004.9690.

[34] Wu JQ, Ma WW, Li G et al. Contents of active organic carbon in soils of different flooding areas in marshy meadow in Gahai wetlands. Wetland Science, 2017, 15(1) : 137-143. [ 吴江琪, 马维伟, 李广等. 尔海湿地沼泽化草甸中不同积水 
区土壤活性有机碳含量. 湿地科学, 2017, 15(1): 137-143.]

[35] Padhy SR, Bhattacharyya P, Dash PK et al. Seasonal fluctuation in three mode of greenhouse gases emission in relation to soil labile carbon pools in degraded mangrove, Sundarban, India. Science of the Total Environment, 2020, 705: 135909. DOI: 10.1016/j.scitotenv.2019.135909.

[36] Hu YF, Peng JJ, Jiang SL et al. Study on soil active organic carbonin different land use patterns ofthe Middle Sichuan Region. Journal of Soil and Water Conservation, 2014, 28(2) : 221-225, 231. [ 胡玉福, 彭佳佳, 蒋双龙等. 川中丘陵区 不同土地利用方式土壤活性有机碳含量特征研究. 水土保持学报, 2014, 28(2)：221-225, 231.]

[37] Yang YG, Yang Y, Geng YQ et al. Effects of different land types on soil enzyme activity in the Qinghai lake region. Wetlands, 2018, 38(4) : 711-721. DOI: 10.1007/s13157-018-1014-9.

[38] Qian HY, Zhou HX, Luo YJ et al. Responses of soil labile organic carbon and carbon pool management index to alpine wetland degradation. Chinese Journal of Ecology, 2020, 39(7) : 2273-2282. DOI: 10.13292/j.1000-4890.202007.018. [ 钱虹宇, 周宏金金, 罗原骏等. 土壤活性有机碳及碳库管理指数对高寒湿地退化的响应. 生态学杂志, 2020,39 ( 7) : 2273-2282.]

[39] Huang LL, Hu WJ, Tao J et al. Soil bacterial community structure and extracellular enzyme activities under different land use types in a long-term reclaimed wetland. Journal of Soils and Sediments, 2019, 19(5) : 2543-2557. DOI: 10.1007/ s11368-019-02262-1.

[40] Xiao Y, Huang ZG, Lu XG. Changes of soil labile organic carbon fractions and their relation to soil microbial characteristics in four typical wetlands of Sanjiang Plain, Northeast China. Ecological Engineering, 2015, 82: 381-389. DOI: 10. 1016/j. ecoleng.2015.05.015.

[41] Shao XX, Yang WY, Wu M. Seasonal dynamics of soil labile organic carbon and enzyme activities in relation to vegetation types in Hangzhou bay tidal flat wetland. PLoS One, 2015, 10(11) : e0142677. DOI: 10.1371/journal.pone.0142677.

[42] Veres Z, Kotroczó Z, Fekete I et al. Soil extracellular enzyme activities are sensitive indicators of detrital inputs and carbon availability. Applied Soil Ecology, 2015, 92: 18-23. DOI: 10.1016/j.apsoil.2015.03.006.

[43] Qi RM, Li J, Lin ZA et al. Temperature effects on soil organic carbon, soil labile organic carbon fractions, and soil enzyme activities under long-term fertilization regimes. Applied Soil Ecology, 2016, 102: 36-45. DOI: 10. 1016/j. apsoil. 2016.02.004. 